\title{
La terbinafina en forma continua fue más efectiva que el itraconazol intermitente en la onicomicosis del pie
}

Double blind, randomised study of continuous terbinafine compared with intermittent itraconazole in treatment of toenail onychomycosis. E Glyn V Evans, Bardur Sigurgeirsson for the LION study group. BMJ 1999:318:1031-1035

\section{Objetivo}

Comparar la eficacia y la seguridad de la terbinafina por vía oral en una toma diaria continua con el itraconazol por vía oral en tomas intermitentes para el tratamiento de la onicomicosis del pie.

\section{Diseño}

Ensayo clínico aleatorizado, doble ciego, de grupos paralelos.

\section{Lugar}

Estudio multicéntrico realizado en 35 centros de seis países europeos: Finlandia, Alemania, Islandia, Italia, Inglaterra y Holanda.

\section{Pacientes}

Hombres y mujeres de 18 a 75 años con diagnóstico clínico de onicomicosis confirmado por resultados positivos en el examen micológico directo y en el cultivo. Se incluyeron sólo aquellos pacientes que presentaban infección por dermatofitos. Se excluyeron a los pacientes que habían recibido tratamiento local en las cuatro semanas previas al estudio o tratamiento sistémico en los 12 meses previos al mismo.

\section{Intervención}

Se aleatorizó a los pacientes en cuatro grupos paralelos: 1) Grupo T12 $(n=126)$ : este grupo recibió $250 \mathrm{mg}$ diarios de terbinafina durante 12 semanas; 2) Grupo T16 ( $n=120)$ : este grupo recibió $250 \mathrm{mg}$ diarios de terbinafina durante 16 semanas; 3 ) Grupo I3 ( $n=126)$ : este grupo recibió 3 ciclos de itraconazol durante 12 semanas. Cada ciclo constaba de una dosis de $400 \mathrm{mg}$ por día durante una semana y tres semanas de descanso; 4) Grupo I4 ( $n=126$ ): este grupo recibió 4 ciclos de itraconazol durante 16 semanas con el mismo esquema que el grupo I3.

\section{Medición de los resultados}

La variable primaria medida fue la curación micológica, definida como resultados negativos en el examen micológico directo y en el cultivo.
Las variables secundarias fueron la curación clínica (100\% de aclaramiento de la uña), la curación completa (curación micológica y clínica), la efectividad clínica (curación micológica y, al menos, $5 \mathrm{~mm}$ de crecimiento de la uña nueva y sana) y la aceptación global del tratamiento por parte del paciente y del médico.

\section{Resultados}

El seguimiento fue de 72 semanas. El análisis fue por intención de tratar.

\begin{tabular}{lllll}
\hline & T12 & T16 & I3 & I4 \\
\hline Curación clínica & $54 \%$ & $60 \%$ & $32 \%$ & $32 \%$ \\
\hline Curación micológica & $76 \%$ & $81 \%$ & $38 \%$ & $49 \%$ \\
\hline Curaciọ́n completa & $46 \%$ & $55 \%$ & $23 \%$ & $26 \%$ \\
\hline Eficacia clínica & $66 \%$ & $71 \%$ & $28 \%$ & $34 \%$ \\
\hline Aceptación del médico & $79 \%$ & $85 \%$ & $52 \%$ & $55 \%$ \\
\hline Aceptación del paciente & $79 \%$ & $79 \%$ & $44 \%$ & $52 \%$ \\
\hline
\end{tabular}

La curación completa (definida como curación micológica y clínica) fue del $46 \%$ y del $55 \%$ para la terbinafina durante 12 y 16 semanas respectivamente, y de $23 \%$ y $26 \%$ para el itraconazol, durante 12 y 16 semanas respectivamente $(p \leq 0,005$ para todas las comparaciones entre terbinafina e itraconazol). La efectividad clínica y la aceptación global del tratamiento por parte del médico y del paciente también fueron superiores en el grupo tratado con terbinafina $(p=0.0001)$. Los efectos adversos más frecuentemente reportados para ambas drogas fueron: náuseas, cefalea, infección del tracto respiratorio superior, dolor lumbar, bronquitis y fiebre. Ambas drogas fueron bien toleradas y no hubo diferencias significativas entre los grupos.

\section{Conclusiones}

El tratamiento de la onicomicosis del pie con 250mg de terbinafina por día, durante 12 o 16 semanas, tuvo una mayor tasa de curación, que con itraconazol intermitente, administrado durante el mismo período.

\section{COMENTARIO}

La onicomicosis es una de las patologías dermatológicas más prevalentes en atención primaria, siendo la prevalencia reportada en adultos del 2 al 4\%1-2. A pesar de no ser un problema mayor de salud, es motivo frecuente de preocupación y consulta de nuestros pacientes. Las alternativas terapéuticas ante este problema son habitualmente el tratamiento por vía oral con imidazólicos como el itraconazol o el fluconazol, o más recientemente el uso de terbinafina. El tratamiento tópico de esta patología es generalmente inefectivo ${ }^{3}$.

Este prolijo estudio demuestra que la terbinafina es claramente superior al itraconazol intermitente (esquema de pulso) para el tratamiento de la onicomicosis del pie. Es importante aclarar que el tratamiento de esta patología no es sencillo, dura mucho tiempo (por lo menos 3 a 4 meses) y que, en el mejor de los casos, la tasa de curación llega al 70\%. Otro aspecto a tener en cuenta es el costo: en Argentina el tratamiento con terbinafina, a dosis de $250 \mathrm{mg}$ por día, cuesta $\$ 360$ si dura 12 semanas y $\$ 480$ si dura 16 semanas. El tratamiento con itraconazol, a dosis de

*Ver Glosario

\section{Dr. Rodolfo Di Paolo}

Unidad de Medicina Familiar y Preventiva. Hospital Italiano de Buenos Aires.

\section{Referencias}

1. Roberts DT. Prevalence of dermatophyte onychomycosis in the United Kingdom: results of an

- omnibus survey. Br J Dermatol 1992; 126(suppl 39): 23-27.

2.Sais G, Jugglà A, Peyŕ J. Prevalence of dermatophyte onychomycosis in Spain: a cross-sectional

study. Br J Dermatol 1995; 132: 758-761.

3. Rubinstein, E. Acné, micosis y dermatitis. En: PROFAM: Programa de Educación a Distancia de Medicina Familiar y Ambulatoria/ Esteban Rubinstein. Buenos Aires: Hospital Italiano de Buenos Aires. Departamento de Docencia e Investigación, c 1999. V8, p $47-49$.

$400 \mathrm{mg}$ por día durante una semana y tres libres, cuesta $\$ 180$ y $\$ 240$ si se indica por 12 y 16 semanas respectivamente. La magnitud de la diferencia de eficacia se puede expresar en NNT: el número necesario a tratar con terbinafina para lograr una cura micológica extra en relación al itraconazol es de aproximadamente tres pacientes, y el NNT para la curación completa es de alrededor de cinco. Ambas drogas pueden producir hepatotoxicidad. Hay controversia aun en cuanto a si deben monitorizarse o no las transaminasas durante el tratamiento. Algunos autores proponen solicitar hepatograma al inicio del tratamiento y luego cada mes y medio, otros sólo si el paciente tiene hepatopatía subyacente o si aparecen síntomas como fatiga, anorexia, ictericia, náuseas o vómitos. En este estudio no se solicitaron transaminasas como parte del seguimiento y los pacientes no presentaron hepatopatía clinica como efecto adverso.

Lamentablemente, no hay aun opciones accesibles para su tratamiento, pero este estudio demuestra claramente que de elegir un tratamiento para la misma, y de poder el paciente acceder al mismo, la terbinafina es la droga de primera elección. 